\title{
A Cobertura Florestal em Paisagens do Médio Vale do Rio Paraíba do Sul
}

\author{
Marcos Paulo dos Santos Pereira ${ }^{1}$, Márcio Rocha Francelino², \\ Jarbas Marçal Queiroz ${ }^{3}$ \\ ${ }^{1}$ Programa de Pós-graduação em Ciências Ambientais e Florestais, Universidade Federal Rural do Rio de Janeiro - UFRRJ, \\ Seropédica/RJ, Brasil \\ ${ }^{2}$ Departamento de Solos, Universidade Federal de Viçosa - UFV, Viçosa/MG, Brasil \\ ${ }^{3}$ Departamento de Ciências Ambientais, Universidade Federal Rural do Rio de Janeiro - UFRRJ, Seropédica/RJ, Brasil
}

\begin{abstract}
RESUMO
A contínua substituição da cobertura florestal pelo cultivo agrícola e a urbanização causaram alterações na maior parte do bioma Mata Atlântica no Brasil. O entendimento da interação entre os fatores físicos, antrópicos e da cobertura vegetal em uma paisagem é de fundamental importância para oferecer subsídios ao planejamento territorial de forma sustentável. Este estudo investigou a influência da altitude, declividade e orientação das vertentes na cobertura florestal em três diferentes paisagens no município de Vassouras, RJ. No geral, as áreas analisadas apresentaram a cobertura florestal fragmentada, porém foi observada uma paisagem com maior cobertura florestal do que pastagens. Entre as variáveis analisadas, a altitude e a declividade apresentaram uma relação positiva com a cobertura florestal. As paisagens estavam inseridas em diferentes contextos socioeconômicos que podem também determinar a distribuição da cobertura florestal atual. A região estudada oferece atributos socioambientais específicos de cada paisagem, cuja compreensão deve ser útil ao planejamento ambiental.
\end{abstract}

Palavras-chave: fragmentação florestal, ecologia de paisagens, uso do solo, pastagens, vassouras.

\section{Forest Cover in Landscapes of the Middle Valley of Paraiba River}

\begin{abstract}
The continuous replacement of forest covers for crops and urban areas changed most of the Atlantic Forest biome in Brazil. Hence, understanding the interaction between the forest cover, physical and anthropic factors in a landscape is essential in order to provide subsidies for sustainable land use. The present study aimed at investigating the influence of the altitude, declivity, and slope orientation on the forest cover of three landscapes in the municipality of Vassouras. In general, Vassouras showed fragmented forest covers, but we observed a landscape covered more by forests than pastures. Among the variables analyzed, altitude and declivity showed a positive relationship with forest cover. The analyzed landscapes were inserted in different socio-economical contexts, which can also affect the current forest cover distribution. The socio-environmental attributes of those landscapes are specific and their understanding can be strategic for environmental planning.
\end{abstract}

Keywords: forest fragmentation, landscape ecology, land use, pastures, vassouras. 


\section{INTRODUÇÃO}

A contínua retirada da cobertura florestal para atividades antrópicas causou a destruição da maior parte do bioma Mata Atlântica (Dean, 2007). Um dos principais elementos que contribuíram para a devastação da Mata Atlântica no Estado do Rio de Janeiro foi o cultivo do café. Iniciado nas terras baixas próximas à capital, o cultivo do café seguiu serra acima, na qual as condições ambientais eram mais favoráveis ao seu desenvolvimento. Na serra fluminense, mais especificamente no médio vale do Paraíba do Sul, o ciclo econômico do café provocou perdas irreparáveis da cobertura florestal (Stein, 1990; Drummond, 1997). Os fazendeiros procuravam sempre novas áreas nas encostas dos morros para iniciar o plantio do café, evitando terrenos já cultivados (Gomes, 2004). As restrições para aquisição de mão-de-obra escrava associadas ao mau uso do solo resultaram em uma queda abrupta da produção de café e no enfraquecimento econômico dos fazendeiros na região (Stein, 1990). Logo após o abandono da atividade cafeeira, a agropecuária foi inserida na paisagem como alternativa, fazendo crescer as áreas ocupadas por pastagens (Stein, 1990). O entendimento dos fatores que determinam a ocorrência dos diversos usos do solo em paisagens modificadas pelo homem pode ajudar na identificação das principais fragilidades ambientais, oferecendo subsídios ao planejamento territorial sustentável (Cabral et al., 2007; Amorim \& Oliveira, 2008).

Estudos realizados em florestas com histórico de exploração têm contribuído para elucidar as principais variáveis bióticas e abióticas que influenciam os padrões de sucessão e de regeneração em florestas tropicais (Guariguata \& Ostertag, 2001). O modo como as variáveis físicas determinam a distribuição da cobertura florestal na paisagem difere entre regiões. Em alguns casos não atuam, em outras agem isoladamente ou em sinergia. A altitude e a declividade do terreno são fatores determinantes na distribuição da cobertura vegetal. As partes mais baixas e de relevo suave são as mais susceptíveis aos efeitos da ação antrópica devido às facilidades de acesso associadas a maior aptidão dos solos para a agricultura (Cabral \& Fiszon, 2004; Silva et al., 2007; Cunha et al., 2012). A orientação das vertentes influencia a exposição do terreno à radiação solar, ventos e chuva, podendo interferir no crescimento da vegetação (Ferreira et al., 2012).
No Estado do Rio de Janeiro, o vale do rio Paraíba do Sul vem sofrendo degradação ambiental desde o século XIX (Drummond, 1997). Para subsidiar ações conservacionistas das florestas no Estado do Rio de Janeiro é necessário entender a sua distribuição e avaliar os condicionantes ambientais que afetam a manutenção e o crescimento da cobertura florestal. A conservação dos recursos naturais nessa região depende em grande parte do uso que se faça dos solos. Entender a atual distribuição da cobertura florestal é essencial para a conservação dos recursos hídricos e da biodiversidade. Neste estudo buscamos, com auxílio de técnicas de sensoriamento remoto, avaliar a associação entre três variáveis ambientais e a ocorrência de cobertura florestal nativa em três paisagens distintas no município de Vassouras. RJ.

\section{MATERIAL E MÉTODOS}

Foi realizado o mapeamento das classes de uso e cobertura do solo na escala 1:5.000 sob o mosaico de três cenas do sistema QuickBird do ano de 2012, em composição colorida com as bandas do visível (RGB), com resolução espacial de 0,60 metro. A vetorização foi realizada em tela, com o uso do software ArcGIS 10 (ESRI, 2010), utilizando-se o sistema de coordenadas UTM (Universal Transversa de Mercator) com Datum WGS-84. Foi gerado um shape vetorial em forma de circunferência com $4 \mathrm{~km}$ de raio, posicionado em diferentes porções territoriais do município. Assim, onde visualmente havia diferenças no uso do solo, foram calculados os percentuais de cada classe de uso (Pastagem, Cobertura Florestal nativa, Área urbana, Área alagada, Massa d'água, Área edificada, Agricultura e Estrada vicinal e Estrada pavimentada). A partir da análise visual dos resultados do mapeamento do uso e cobertura do solo foram identificados três padrões, os quais, quando associados com o meio físico, possibilitaram distinguir diferentes paisagens que formavam um gradiente com variações nas áreas de uso antrópico e de cobertura florestal:

Paisagem A - Localizada no sudoeste do município, apresenta relevo mais acidentado e mais elevado, apresentando como principal tipo de solo distrófico o Cambissolo Háplico Tb;

Paisagem B - Localizada na região central do município, apresentando relevo ondulado e predomínio de Latossolos de baixa fertilidade 
natural em áreas fortemente afetadas por erosão hídrica;

Paisagem C - Apresenta relevo suave ondulado e os solos mais férteis do município (Argissolo Vermelho-Amarelo Eutrófico) (Figura 1).

Assim, após a classificação do uso do solo em escala detalhada em cada uma das três paisagens selecionadas anteriormente, os dados de altitude (em metros) foram obtidos do modelo digital de elevação (MDE) do SRTM (Shuttle Radar Topography Mission), com resolução espacial de 90 metros, os quais foram convertidos para pontos cotados e posteriormente interpolados utilizando-se o algoritmo Topo to Raster do programa Arcgis 10 de forma a gerar um novo MDE, com resolução espacial de 20 metros. Esse novo MDE foi utilizado para gerar a declividade (em graus) e a orientação das vertentes (Norte, Sul, Leste, Oeste), ambas no programa Arcgis 10 , o primeiro através do comando Slope e o segundo com o comando Aspect. A declividade foi separada em 9 classes com intervalo de 5 graus. Os dados de solos foram obtidos de Carvalho et al. (2003).
Com o objetivo de explicar as diferenças no uso e cobertura do solo das paisagens selecionadas foram investigadas três variáveis abióticas: altitude, declividade, orientação de vertentes. Para compreender a relação da presença dos fragmentos florestais com as referidas variáveis foi utilizado o comando Zonal Statistics as Table do programa Arcgis 10, no qual cada feição de uso extrai os valores máximo, mínimo, amplitude, média e desvio-padrão das três variáveis apreciadas.

Todas as variáveis geradas no ArcGIS 10 foram convertidas para a extensão .dbf, editadas em planilha Excel e relacionadas com a presença de cobertura florestal (fragmentos florestais) nas três diferentes paisagens.

\section{RESULTADOS}

\subsection{Uso do solo}

Nas três paisagens, foram mapeados aproximadamente 15 mil hectares. No geral, foi possível observar um predomínio das áreas de pastagens em relação à cobertura florestal nativa (fragmentos florestais de

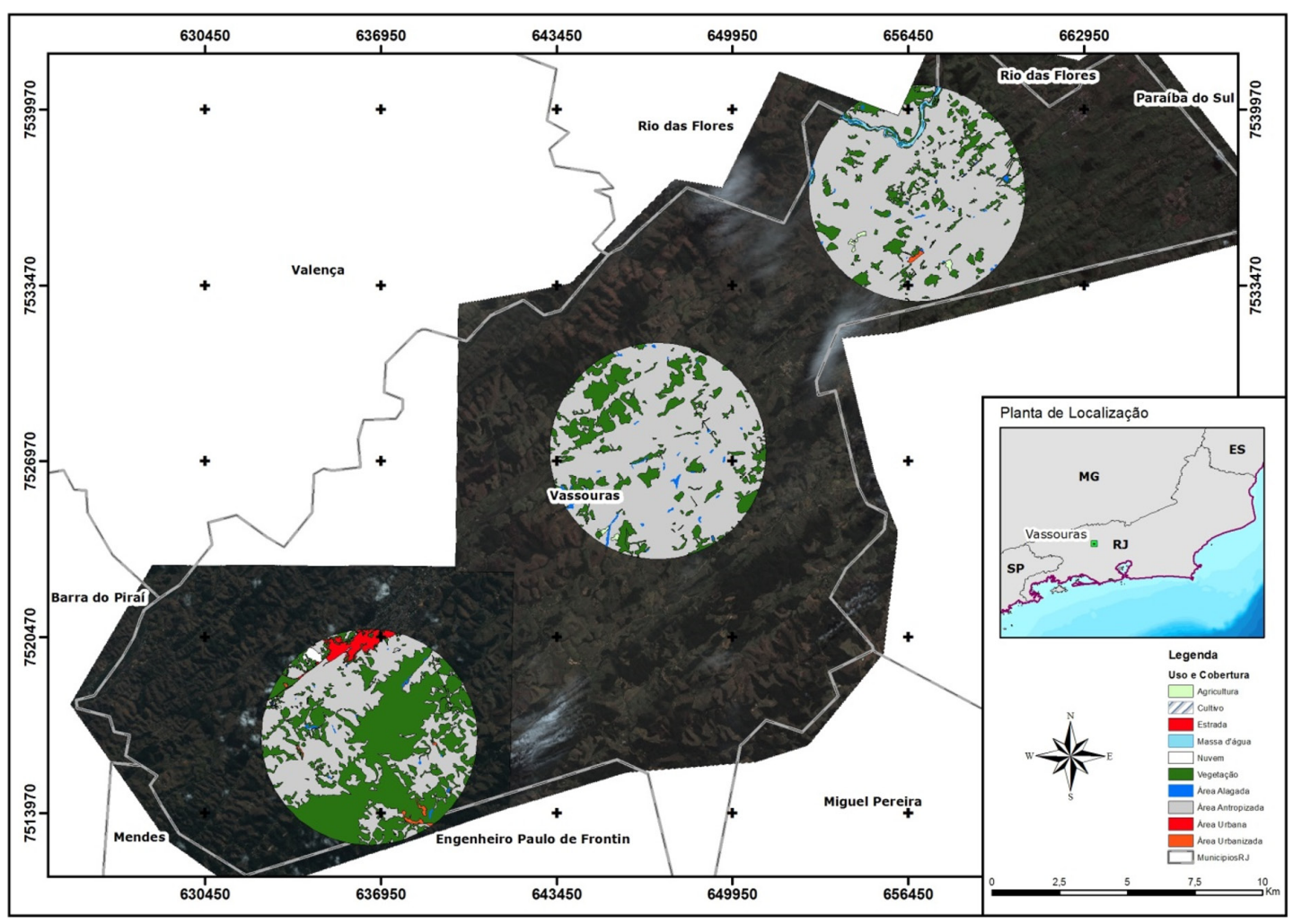

Figura 1. Localização das três paisagens estudadas no município de Vassouras, RJ, Brasil.

Figure 1. Position of the three landscapes studied in the municipality of Vassouras, RJ, Brazil. 
Floresta Estacional Semidecidual), 68,9\% e 28,4\%, respectivamente. Os 2,7\% restantes representaram os outros usos: Área urbana, Área alagada, Massa dágua, Área edificada, Agricultura e Estrada.

Como tendenciado através dos métodos empregados (disposição das áreas circulares em diferentes regiões do município), as paisagens apresentaram diferenças em relação ao uso do solo. Entre as paisagens, somente a paisagem A apresentou maior cobertura florestal nativa do que de pastagens, de $50 \%$ e $45 \%$, respectivamente, os $5 \%$ restantes compreenderam os outros usos. Na paisagem B foi observada uma maior porcentagem de áreas com pastagens $(78,8 \%)$ em relação à cobertura florestal nativa $(19,6 \%)$. E na paisagem $\mathrm{C}$, a porcentagem de área com pastagens foi ainda maior: $85 \%$ da área total mapeada (Tabela 1 ).

A cobertura florestal nativa se apresentou distribuída, em sua maior parte (70\%), em pequenos fragmentos florestais, com área menor ou igual a 5 hectares. Fragmentos florestais com área maior que 50 hectares representaram apenas $2 \%$ da área de cobertura florestal. As paisagens de trabalho também apresentaram diferenças em relação à fragmentação da cobertura florestal nativa. A cobertura florestal da paisagem A se apresentou distribuída em 118 fragmentos, com apenas uma área maior que 100 hectares. A paisagem B apresentou 102 fragmentos florestais, sendo apenas dois com área maior que 100 hectares. Na paisagem C foram quantificados 167 fragmentos e apenas 9 apresentaram área maior que 15 hectares. A paisagem $\mathrm{C}$ apresentou alta frequência de pequenos fragmentos nas classes abaixo de 5 hectares quando comparada com a paisagem $A$, que apresentou maior frequência nas classes de tamanho maiores que 15 hectares (Figura 2).

\subsection{Ambiente físico e uso do solo}

\subsubsection{Altitude}

A área total mapeada, nas três paisagens, apresentou $60 \%$ de sua porção territorial distribuída entre 450 e 600 metros de altitude. Aproximadamente 4\% da área se encontrava em altitude maior que 600 metros. Analisando a variação da altitude entre as paisagens de trabalho foi possível observar que a paisagem $\mathrm{A}$ apresentou maior amplitude, com terrenos dispostos entre 500 e 900 metros; seguida da paisagem B, com terrenos entre 400 e 600 metros; e pela paisagem C, cujos terrenos se distribuíram entre 300 e 650 metros. Portanto, as paisagens representam um perfil altimétrico na região estudada. A paisagem A apresentou $80 \%$ de sua porção territorial concentrada entre 500 a $650 \mathrm{~m}$ de altitude, com $40 \%$ do total (2.254 hectares) entre 550 e 600 m. A paisagem B apresentou $80 \%$ da porção territorial mapeada entre 450 e 550 metros de altitude.

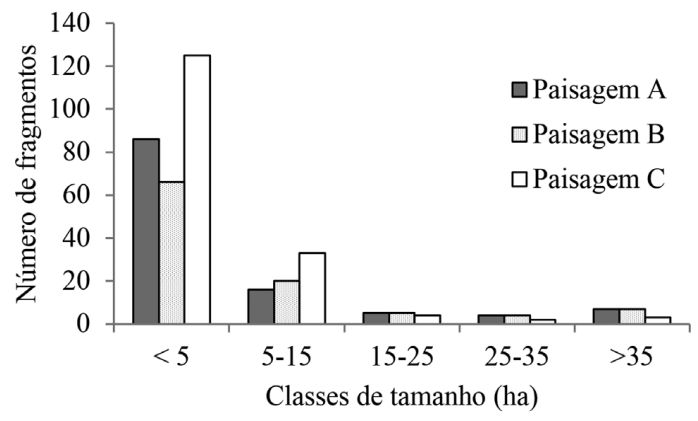

Figura 2. Número de fragmentos distribuídos por classe de área (ha) em três paisagens do município de Vassouras, RJ.

Figure 2. Number of fragments in each class of size (ha) for the three landscape of Vassouras, RJ.

Tabela 1. Uso do solo em três paisagens no município de Vassouras, RJ.

Table 1. Land use in three landscape of Vassouras, RJ.

\begin{tabular}{lccccc} 
& \multicolumn{5}{c}{ Área (ha) } \\
\cline { 2 - 6 } Classe de uso & $\mathbf{A}$ & $\mathbf{B}$ & $\mathbf{C}$ & Total & (\%) \\
\cline { 2 - 6 } Pastagem & $2.254,0$ & $3.862,6$ & $4.018,9$ & $10.135,6$ & 68,9 \\
\hline Floresta & $2.451,1$ & 963,6 & 770,8 & $4.185,5$ & 28,4 \\
\hline Área urbana & 151,7 & 0 & 0 & 151,7 & 1,0 \\
\hline Área alagada & 15,6 & 49,0 & 14,7 & 79,4 & 0,5 \\
\hline Massa d'água & 0 & 0 & 65,7 & 65,7 & 0,4 \\
Agricultura & 20,4 & 12,1 & 15,4 & 48,1 & 0,3 \\
Estrada & 1,8 & 13,9 & 18,4 & 34,2 & 0,2 \\
Total & $4.901,41$ & $4.901,46$ & $4.904,23$ & $14.707,10$ & 100,0 \\
\hline
\end{tabular}


Apenas 3\% de sua área se apresentou em altitudes maiores que $600 \mathrm{~m}$. Na paisagem $\mathrm{C}$ foi possível observar que um terço (33\%) de sua área estava no intervalo entre 350 e 400 metros e menos de 3\%, acima dos $500 \mathrm{~m}$ de altitude. Sendo assim, pode-se dizer que a paisagem A ocupa uma porção superior e a paisagem C, uma porção inferior na bacia hidrográfica do Rio Paraíba do Sul (Figura 3).

Em relação ao uso do solo, até 600 metros de altitude houve predomínio de pastagens e acima dessa cota, predomínio da cobertura florestal. Na paisagem A, a distribuição do uso da terra (cobertura florestal e pastagem) em relação à altitude do terreno seguiu o padrão demonstrado para toda a região estudada. Ou seja, até 600 metros predominaram as pastagens e acima, a cobertura florestal. Já na paisagem $B$, a cobertura florestal se concentrou entre 600 e 700 metros de altitude. Na paisagem C, a cobertura florestal se distribuiu entre 300 e 500 metros de altitude (Figura 4A-D).

\subsubsection{Declividade}

Aproximadamente $60 \%$ da área total mapeada tinha declividade entre $5^{\circ}$ e $20^{\circ}$. A classe mais suave, $0^{\circ}$ a $5^{\circ}$, ocupou aproximadamente $15 \%$ da área total e as classes acima de $20^{\circ}$ representaram 25\%. Dentre as paisagens foi possível observar que as classes de declividade abaixo de $15^{\circ}$ foram mais frequentes nas paisagens $\mathrm{B}$ e $\mathrm{C}$ e, acima de $15^{\circ}$, a ocorrência maior foi na paisagem A (Figura 5).
Em relação ao uso do solo nas diferentes classes de declividade, observou-se um aumento gradativo da cobertura florestal, com consequente redução na cobertura por pastagem, com o aumento da declividade do terreno. Na paisagem A houve pouca variação no uso do solo em relação à declividade do terreno. $\mathrm{Na}$ paisagem B, a cobertura florestal aumentou com o aumento da declividade do terreno, enquanto na paisagem C o padrão foi oposto ao da B (Figura 6).

\subsubsection{Orientação de vertentes}

Praticamente não houve variação no uso do solo em relação às faces de exposição em toda a região estudada. A distribuição do uso e cobertura do solo dentro das paisagens apresentou padrão similar ao de toda região, praticamente sem variação no uso do solo em função das faces de exposição (Figura 7).

\section{DISCUSSÃO}

A cobertura florestal encontrada atualmente no município de Vassouras é resultado do processo histórico de ocupação das terras do município, com destaque para a cultura do café, seguida da pecuária leiteira, e dos processos regenerativos da vegetação nativa em áreas abandonadas. Durante o ciclo do café quase nenhuma área ou feição do terreno foi poupada. A lavoura cafeeira procurava solos nunca antes cultivados, em terras bem drenadas e nas encostas mais altas das propriedades (Stein, 1990; Gomes, 2004).

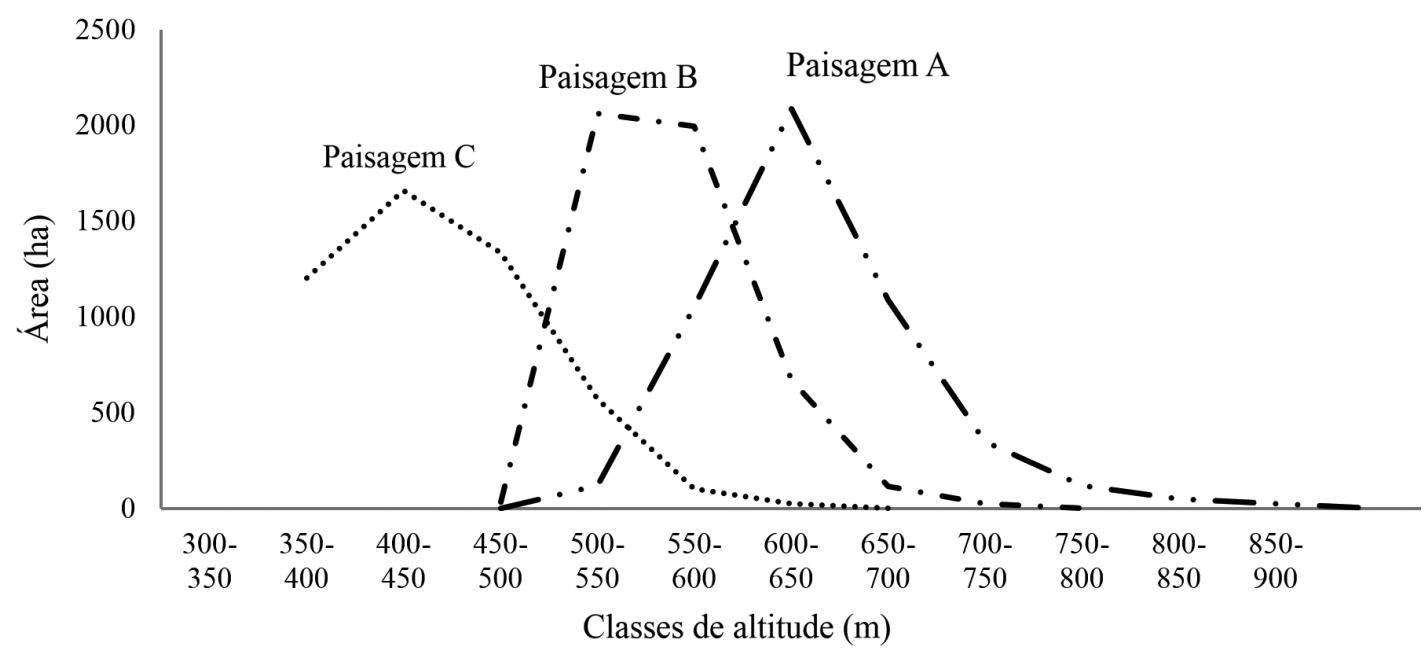

Figura 3. Distribuição das áreas das três paisagens em relação às classes de altitude no município de Vassouras, RJ. Figure 3. Distribution of land size (ha) in each class of altitude (meters) for the three landscape in Vassouras, RJ. 


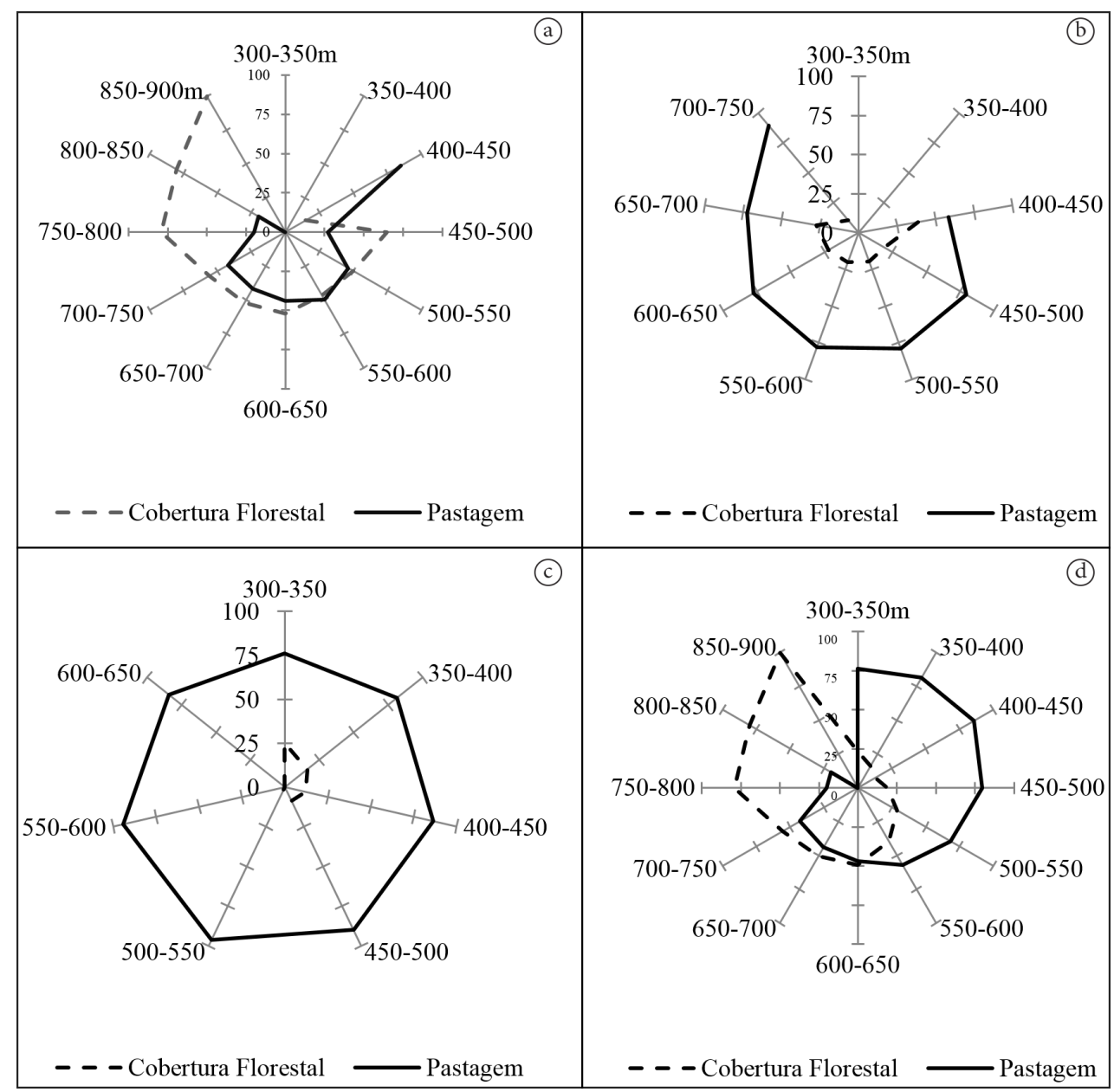

Figura 4. Distribuição dos percentuais de pastagem e de cobertura florestal em função das classes de altitude (m), no município de Vassouras, RJ. (a) Paisagem A; (b) Paisagem "B”; (c) Paisagem C; (d) Total da área amostrada.

Figure 4. Percent distribution of pastures and forest cover per class of altitude (m) in Vassouras, RJ. (a) Landscape "A"; (b) Landscape "B"; (c) Landscape "C"; (d) Total sampled area.

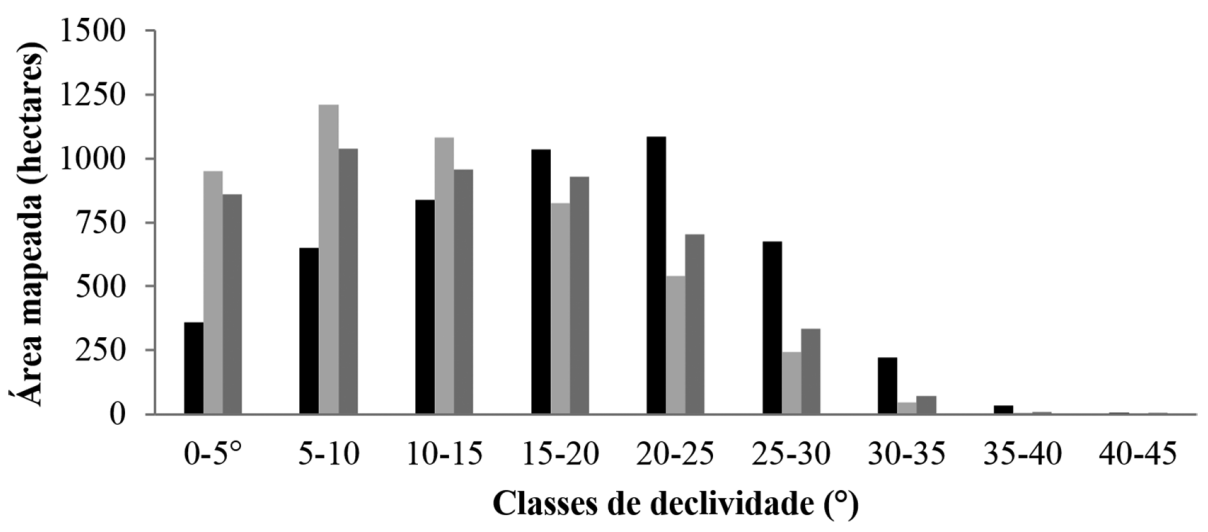

- Paisagem A $\backsim$ Paisagem B $\backsim$ Paisagem C

Figura 5. Classes de declividade em três paisagens no município de Vassouras, RJ.

Figure 5. Classes of slope for the three landscapes of Vassouras, RJ. 


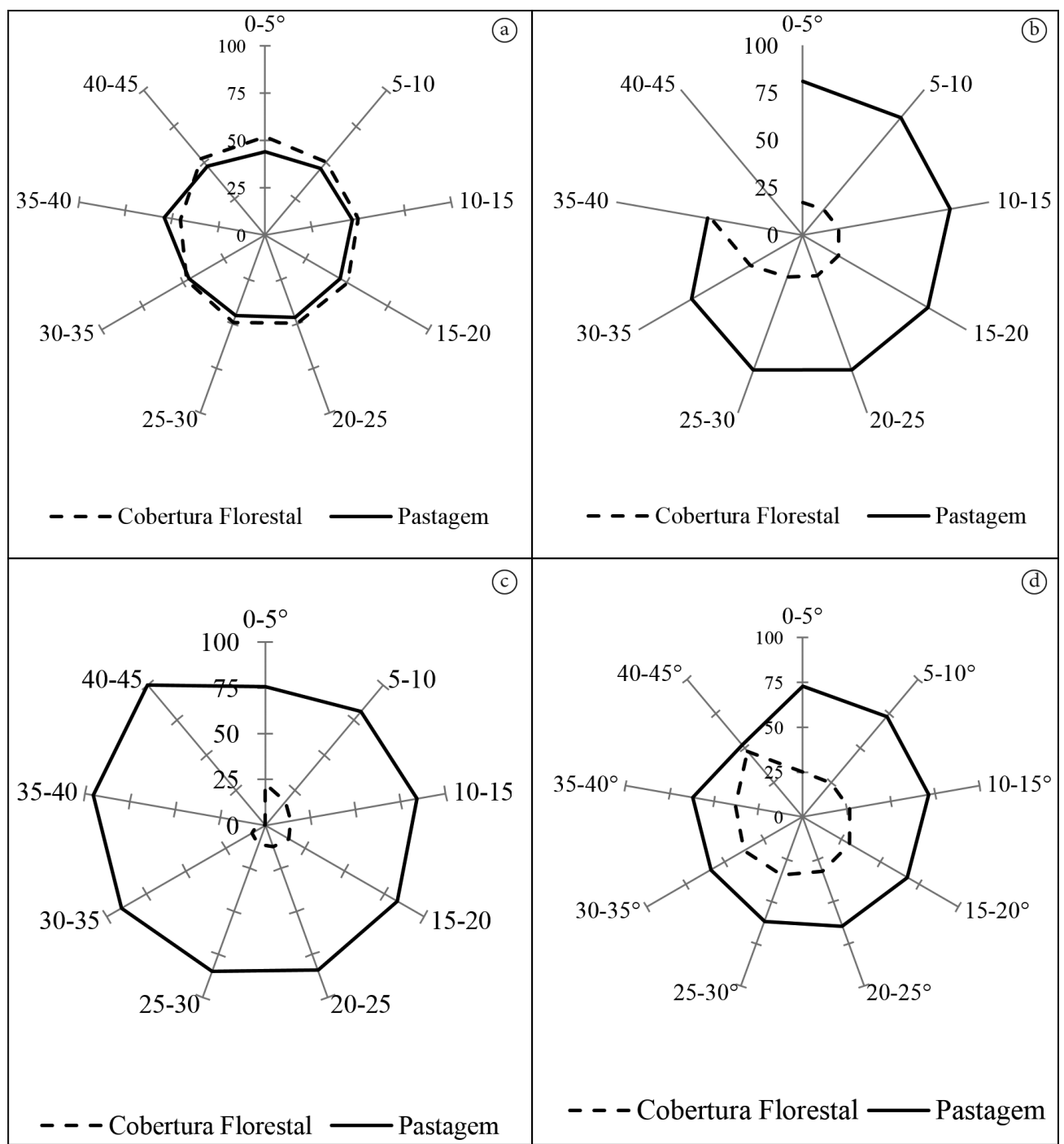

Figura 6. Distribuição dos percentuais de pastagem e de cobertura florestal em função das classes de declividade, em graus, emVassouras, RJ. (a) Paisagem A; (b) Paisagem B; (c) Paisagem C; (d) Total da área amostrada.

Figure 6. Percent distribution of pastures and forest cover among slope classes in Vassouras, RJ. (a) Landscape "A"; (b) Landscape "B"; (c) Landscape "C"; (d) Total sampled area.

Em pouco tempo, as florestas estacionais semideciduais da região de Vassouras deram lugar às lavouras de café e em pouco tempo também essas lavouras entraram em declínio e foram sendo substituídas por áreas de pastagem destinadas à criação de gado (Stein, 1990).

Os relatos históricos mencionam que a lavoura cafeeira no Município de Vassouras não poupou terras, ocupando a maior parte da área disponível (Stein, 1990). Nossos dados revelaram que, atualmente, as áreas com maior cobertura florestal situam-se em terrenos de maior altitude e declividade. É possível que com o declínio do ciclo econômico baseado na lavoura cafeeira as áreas menos propícias para a agropecuária tenham sido abandonadas e a floresta tenha se regenerado. Desse processo resultou uma cobertura florestal cuja principal característica é o alto grau de fragmentação. Embora na Mata Atlântica a cobertura florestal esteja distribuída em sua maioria em fragmentos com área inferior a 50 hectares (Ribeiro et al., 2009), em Vassouras a fragmentação é mais intensa, com a maioria dos fragmentos com área inferior a 5 hectares. Essas pequenas manchas de florestas semidecíduas são importantes para a conservação por se tratarem de fitofisionomia extremamente ameaçada do bioma 


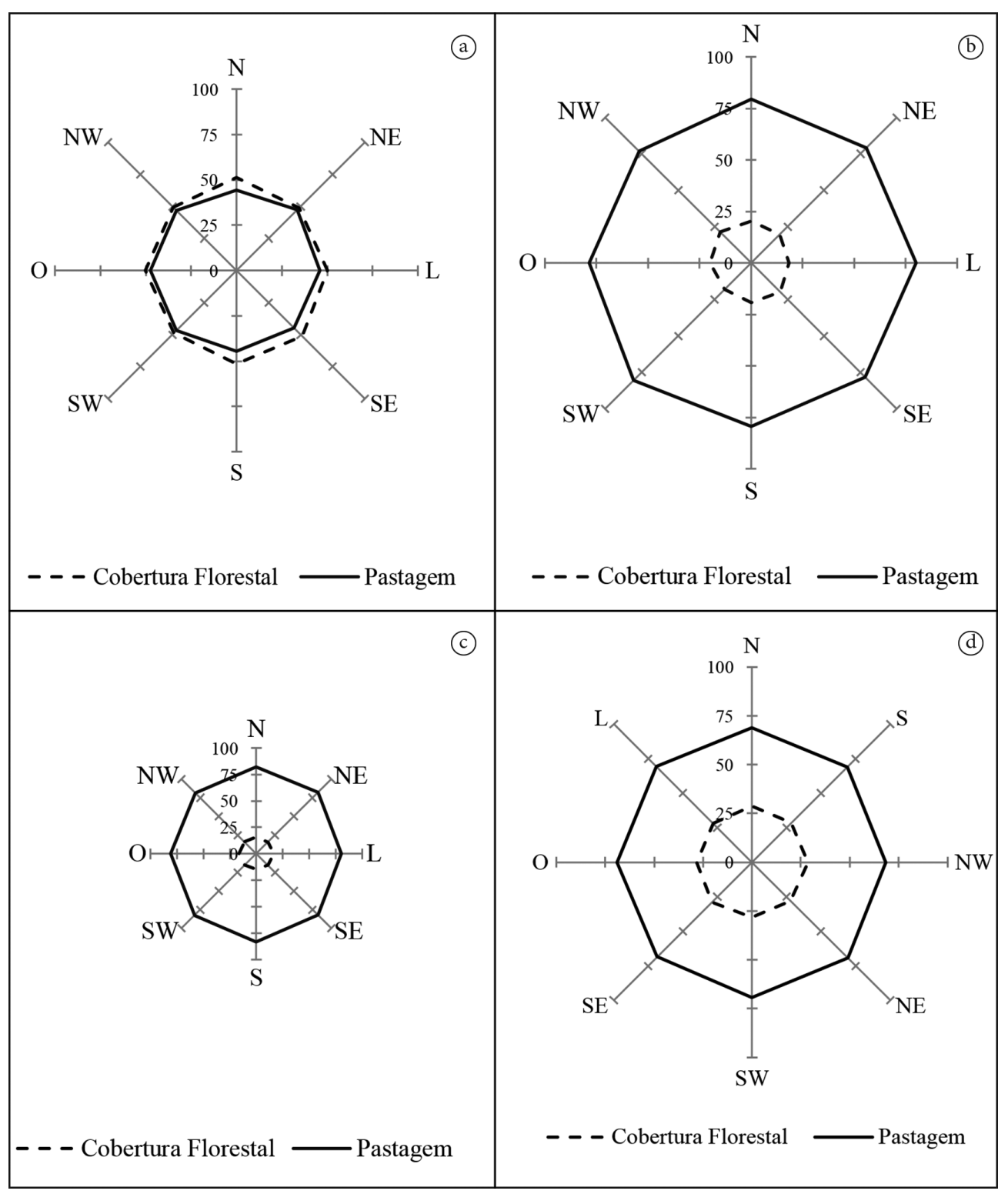

Figura 7. Distribuição dos percentuais de pastagem e de cobertura florestal em função da orientação das vertentes, em Vassouras, RJ. (a) Paisagem A; (b) Paisagem B; (c) Paisagem C; (d) Total da área amostrada.

Figure 7. Percent distribution of pastures and forest cover among slope orientation sides, Vassouras, RJ. (a) Landscape "A"; (b) Landscape "B"; (c) Landscape "C"; (d) Total sampled area.

Mata Atlântica (Lopes et al., 2012; Zani et al., 2011). Em Vassouras, elas encontram-se muito ameaçadas de degradação devido ao tamanho reduzido dos fragmentos e à ausência de unidades de conservação que poderiam dar alguma proteção às paisagens em que se inserem (Viana \& Pinheiro, 1998). Devido ao alto grau de destruição da Mata Atlântica, esses fragmentos representam os últimos refúgios para muitas espécies da fauna e flora nativas (Turner \&
Corlett, 1996). É urgente a necessidade de estudos sobre a biodiversidade que ainda pode ser encontrada nessa região, como estratégia para alavancar projetos para sua conservação.

Apesar da devastação da cobertura florestal em Vassouras (Stein, 1990), ainda foi possível encontrar uma região onde há predomínio de florestas. Essa região situa-se nos arredores da cidade de Vassouras, amostrada na paisagem A. Esse resultado pode surpreender 
inicialmente, uma vez que a cobertura florestal deve ser inversamente relacionada com a proximidade de centros urbanos e densidade de estradas (Freitas et al., 2010). No entanto, a maior cobertura florestal próxima da malha urbana pode estar ligada à menor presença da agropecuária tradicional em favor de uma utilização das terras para turismo rural. Além disso, a regeneração da floresta nessas áreas inseridas na paisagem A pode ter sido favorecida pela proximidade com outras áreas de florestas situadas ao sul, sobretudo nos arredores de Mendes e Sacra Família do Tinguá, que historicamente se desenvolveram como áreas para veraneio da população do Rio de Janeiro (Fridman, 2008). A proximidade de áreas de florestas influencia na regeneração da vegetação devido à maior probabilidade da chegada de propágulos das fontes vizinhas (Teixeira et al., 2009).

As diferenças na porcentagem de cobertura florestal entre as três paisagens estudadas também podem estar relacionadas com as diferenças de altitude e de declividade dos terrenos (Silva et al., 2007; Cabral \& Fiszon, 2004). Nas paisagens B e C, a menor altitude e o relevo mais suave facilitam sua ocupação pela agropecuária tradicional. Na paisagem $\mathrm{A}$, com altitude maior, houve um predomínio de florestas em relação às pastagens a partir dos $600 \mathrm{~m}$. Já nas paisagens $\mathrm{B}$ e $\mathrm{C}$, com predomínio de cotas altimétricas inferiores a $600 \mathrm{~m}$, essa relação não apareceu. Isso pode estar relacionado à exploração da região para cultivo de café, pois as plantas crescem bem em clima mais ameno (Ferreira et al., 2012).

Em relação à declividade, no geral houve aumento da cobertura florestal nos terrenos mais acidentados, mas o padrão foi mais claro na paisagem $B$ do que nas outras duas. Normalmente espera-se que em terrenos muito declivosos a cobertura florestal seja dominante por causa das limitações de uso desses locais para a agropecuária tradicional (Silva et al. 2007). No caso de Vassouras é possível sugerir que, conforme relatos históricos (Stein, 1990), no auge do ciclo do café a grande maioria das terras era usada para a cultura, mas depois, com o declínio, os piores terrenos devem ter sido os primeiros a ser abandonados. Isso pode ter ocorrido em parte das terras amostradas nas paisagens A e B. A paisagem $C$, no entanto, com sua baixa altitude e relevo suave continuou sendo área predominantemente de uso agropecuário, com cobertura predominante de pastagens.
Em relação à orientação das vertentes e sua relação com a cobertura florestal, alguns autores encontraram mais florestas nas encostas voltadas para sul (Oliveira et al., 1995; Caldas, 2006), já que nesse hemisfério as faces de exposição são mais úmidas e sofrem menos com temperaturas elevadas do que aquelas voltadas para o norte, o que acaba favorecendo a regeneração da floresta (Ferreira et al., 2012). Entretanto, a distribuição da cobertura florestal nas paisagens estudadas em Vassouras foi homogênea entre as diferentes faces de exposição, similar ao encontrado em uma área de floresta montana densa no interior de São Paulo (Silva et al., 2007). É possível que outros fatores tenham agido, impedindo a detecção do padrão esperado, pois a regeneração de florestas em áreas muito impactadas pode ocorrer independentemente dos fatores abióticos (Silveira \& Silva, 2010). No caso de Vassouras, a distribuição da cobertura florestal sofreu grande influência das lavouras de café. Durante a exploração do café na região, as recomendações eram que, nas áreas de baixa altitude, mais quentes, $\mathrm{o}$ café fosse cultivado nas encostas voltadas para o sul, já nas áreas de altitude mais elevada, mais frias, que o café fosse cultivado em encostas voltadas para o norte (Valverde, 1967). Não encontramos informações de que essas recomendações eram seguidas pelos fazendeiros. Esse padrão de utilização das encostas para o cultivo de café poderia ter influenciado a atual distribuição da cobertura florestal, mas com os dados de que dispomos e dada a ausência de registros históricos do uso das encostas, não podemos concluir sobre as causas para a distribuição homogênea das florestas em relação às faces de exposição das encostas.

As paisagens mais degradadas necessitam de um plano para recuperação da cobertura florestal, com objetivo de proteger os recursos hídricos e conter a erosão dos solos (Moulton \& Souza, 2006), principalmente por se tratar de áreas de contribuição do principal rio do Sudeste, o Paraíba do Sul (Marengo \& Alves, 2005). É preciso reverter o quadro de degradação para que a região deixe de ser considerada a mais devastada do território fluminense (Drummond, 1997). As ações devem procurar estimular a regeneração e a recuperação da vegetação arbórea nas áreas degradadas e a preservação da cobertura florestal existente. A proximidade do município com a região metropolitana do Rio de Janeiro cria oportunidades e riscos para a conservação dos recursos naturais. Atividades geradoras de renda 
com baixo impacto sobre as paisagens, como é o caso do turismo rural, que combina atividades agrícolas e não agrícolas (Brasil, 2010), e a implantação de sistemas florestais e agroflorestais, que podem gerar renda e auxiliar na tarefa de recuperação das paisagens degradadas (Ranta et al., 1998; Gomes, 2004; Francelino et al., 2012) representam alternativas que poderiam ajudar na conservação dos recursos naturais. Por outro lado, a proximidade com grandes centros urbanos pode fazer aumentar o número de construções e estradas e acabar contribuindo para a redução da cobertura florestal (Freitas et al., 2010).

\section{CONSIDERAÇÕES FINAIS}

Os fragmentos florestais na paisagem A estão relativamente bem próximos uns dos outros e de certa forma a paisagem como um todo pode ser considerada mais conservada, conforme pode ser observado no mapeamento de uso e cobertura do solo. Parte dessa paisagem está dentro do corredor Tingua-Bocaina para conservação da biodiversidade. $\mathrm{O}$ desenvolvimento de atividades menos impactantes e capazes de gerar renda deve seguir o modelo que utiliza as florestas para a conservação da paisagem e a oferta de serviços ambientais, com garantias de sustentabilidade em longo prazo.

Sugere-se que as paisagens mais antropizadas, paisagem B e, principalmente, paisagem $\mathrm{C}$, em áreas de relevo pouco movimentado e solos desenvolvidos, poderiam ser alvo de projetos de reflorestamento. A produção florestal poderia proporcionar a proteção do solo, dos recursos hídricos e da biodiversidade, ajudando na manutenção dos serviços ambientais. Ressalta-se que as ações devem ser embasadas na adequação ambiental das propriedades rurais, contemplando a legislação ambiental.

\section{AGRADECIMENTOS}

Ao colega André Barbosa Vargas pelo auxílio na análise de dados. Ao revisor anônimo pelas sugestões em versão prévia do manuscrito.

\section{STATUS DA SUBMISSÃO}

Recebido: 23 fev., 2015

Aceito: 15 maio, 2016

\section{${ }^{*}$ AUTOR(ES) PARA CORRESPONDÊN-}

\section{CIA}

\section{Jarbas Marçal Queiroz}

Departamento de Ciências Ambientais, Universidade Federal Rural do Rio de Janeiro UFRRJ, Rodovia BR 465, Km 7, CEP 23890-000, Seropédica, RJ, Brasil

e-mail: jarquiz@gmail.com

\section{APOIO FINANCEIRO}

JMQ agradece o apoio financeiro da FAPERJ

(Processo 101.472/2010).

\section{REFERÊNCIAS}

Amorim RR, Oliveira RC. As unidades de paisagem como uma categoria de análise geográfica: $\mathrm{O}$ exemplo do Município de São Vicente-SP. Sociedade \& Natureza 2008; 20(2): 177-198. http://dx.doi.org/10.1590/S198245132008000200011.

Brasil. Ministério do Turismo. Turismo rural: orientações básicas. 2. ed. Brasília: Ministério do Turismo; 2010. 68 p.

Cabral DC, Fiszon JT. Padrões sócio-espaciais de desflorestamento e suas implicações para a fragmentação florestal: estudo de caso na Bacia do Rio Macacu, RJ. Scientia Forestalis 2004; 66: 13-24.

Cabral DC, Freitas SR, Fiszon JT. Combining sensors in landscape ecology: imagery-based and farm-level analysis in the study of human-driven forest fragmentation. Sociedade \& Natureza 2007; 19(2): 69-87. http://dx.doi. org/10.1590/S1982-45132007000200005.

Caldas AJFS. Geoprocessamento e análise ambiental para a determinação de corredores de habitat na Serra da Concórdia, Vale do Paraíba, RJ [dissertação]. Seropédica: Universidade Federal Rural do Rio de Janeiro; 2006.

Carvalho A Fo, Lumbreras JF, Wittern KP, Lemos AL, Santos RD, Calderano B Fo, Calderano SB, Oliveira RP, Aglio MLD, Souza JS, Chaffin CE. Mapa de reconhecimento de baixa intensidade dos solos do estado do Rio de Janeiro. Rio de Janeiro: Embrapa Solos; 2003. 1 Mapa, color. Escala 1:250.000

Cunha JEBL, Rufino IAA, Silva BB, Chaves IB. Dinâmica da cobertura vegetal para a Bacia de São João do Rio do Peixe, $\mathrm{PB}$, utilizando-se sensoriamento remoto. Revista Brasileira de Engenharia Agrícola e Ambiental 2012; 16(5): 539-548. http://dx.doi.org/10.1590/S1415-43662012000500010.

Dean W. A ferro e fogo: a história e a devastação da mata atlântica brasileira. São Paulo: Companhia das Letras; 2007. 484 p.

Drummond JA. Devastação e preservação ambiental no Rio de Janeiro. Niterói: EDUFF; 1997. 
ESRI. ArcGIS - ArcMap 10 help on line. 2010 [citado em 2011 nov. 20]. Disponível em: http://help.arcgis.com/en/ arcgisdesktop/10.0/help/index.html\#//00170000009r000000

Ferreira WPM, Ribeiro MF, Fernandes-Filho EI, Castro CCR, Souza CF. As características térmicas das faces noruega e soalheira como fatores determinantes do clima para a cafeicultura de montanha. Documentos: Embrapa Café 2012; 10: 1-34.

Francelino MR, Rezende EMC, Silva LDB. Proposta para zoneamento ambiental de plantio de eucalipto. Cerne 2012; 18(2): 275-283. http://dx.doi.org/10.1590/S010477602012000200012 .

Freitas SR, Hawbaker TJ, Metzger JP. Effects of roads, topography, and land use on forest cover dynamics in the Brazilian Atlantic Forest. Forest Ecology and Management 2010; 259(3): 410-417. http://dx.doi.org/10.1016/j. foreco.2009.10.036.

Fridman F. As cidades e o café. Revista Brasileira de Gestão e Desenvolvimento Regional 2008; 4: 27-48.

Gomes ML. Ouro, posseiros e fazendas de café. A ocupação e a degradação ambiental da região das Minas do Canta Gallo na província do Rio de Janeiro [tese]. Seropédica: Programa de Pós-graduação em Desenvolvimento, Agricultura e Sociedade, Universidade Federal Rural do Rio de Janeiro; 2004.

Guariguata MR, Ostertag R. Neotropical secondary forest succession: changes in structural and funcional characteristics. Forest Ecology and Management 2001; 148(1-3): 185-206. http://dx.doi.org/10.1016/S03781127(00)00535-1.

Lopes SF, Schiavini I, Oliveira AP, Vale VS. An ecological comparison of floristic composition in seasonal semideciduous forest in Southeast Brazil: implications for conservation. International Journal of Forestry Research 2012; 2012: 1-14. http://dx.doi.org/10.1155/2012/537269.

Marengo JA, Alves LM. Tendências hidrológicas da bacia do rio Paraíba do Sul. Revista Brasileira de Meteorologia 2005; 20(2): 215-226.

Moulton TP, Souza ML. Conservação com base em bacias hidrográficas. In: Rocha CFD, Bergallo HG, Van-Sluys M, Alves MAS, editores. Biologia da conservação: essências. São Carlos: Editora Rima; 2006. p. 157-181.

Oliveira RR, Zau AS, Lima DF, Silva MBR, Vianna MC, Sodre DO et al. Significado ecológico da orientação de encostas no maciço da Tijuca, Rio de Janeiro. Oecologia
Brasiliensis 1995; 1(1): 523-541. http://dx.doi.org/10.4257/ oeco.1995.0101.28.

Ranta P, Blom T, Niemelä J, Joensuu E, Siitonen M. The fragmented Atlantic rain forest of Brazil: size, shape and distribution of forest fragments. Biodiversity and Conservation 1998; 7(3): 385-403. http://dx.doi. org/10.1023/A:1008885813543.

Ribeiro MC, Metzger JP, Martensen AC, Ponzoni FJ, Hirota MM. The Brazilian Atlantic Forest: how much is left, and how is the remaining forest distributed? Implications for conservation. Biological Conservation 2009; 142(6): 1141 1153. http://dx.doi.org/10.1016/j.biocon.2009.02.021.

Silva WG, Metzger JP, Simões S, Simonetti C. Relief influence on the spatial distribution of the Atlantic Forest cover on the Ibiúna Plateau, SP. Brazilian Journal of Biology = Revista Brasileira de Biologia 2007; 67(3): 403-411. PMid:18094822. http://dx.doi.org/10.1590/ S1519-69842007000300004.

Silveira CS, Silva VV. Dinâmicas de regeneração, degeneração e desmatamento da vegetação provocadas por fatores climáticos e geomorfológicos: uma análise geoecológica através de sig. Revista Árvore 2010; 34(6): 1025-1034. http://dx.doi.org/10.1590/S0100-67622010000600008.

Stein S. Vassouras: um município brasileiro do café, 1850 1900. Rio de Janeiro: Nova Fronteira; 1990. 314 p.

Teixeira AMG, Soares-Filho BS, Freitas SR, Metzger JP. Modeling landscape dynamics in an Atlantic Rainforest region: implications for conservation. Forest Ecology and Management 2009; 257(4): 1219-1230. http://dx.doi. org/10.1016/j.foreco.2008.10.011.

Turner IM, Corlett RT. The conservation value of small, isolated fragments of lowland tropical rain forest. Trends in Ecology \& Evolution 1996; 11(8): 330-333. PMid:21237864. http://dx.doi.org/10.1016/0169-5347(96)10046-X.

Valverde O. A fazenda de café escravocrata no Brasil. Revista Brasileira de Geografia 1967; 29(1): 37-81.

Viana VM, Pinheiro LAFV. Conservação da biodiversidade em fragmentos florestais. Série Técnica IPEF 1998; 12(32): 25-42.

Zani MV, Abreu MB, Cruz CBM. Detecção de mudanças no período de 1994 a 2007 nos remanescentes florestais na Região Turístico-Cultural do Médio Paraíba - RJ. In: Anais XV Simpósio Brasileiro de Sensoriamento Remoto - SBSR; 2011; Curitiba. São José dos Campos: INPE; 2011. p. 2905. 